\title{
Identifying the genetic components underlying the pathophysiology of movement disorders
}

\author{
This article was published in the following Dove Press journal: \\ The Application of Clinical Genetics \\ 21 June 201 I \\ Number of times this article has been viewed
}

\author{
Mario Ezquerra \\ Yaroslau Compta \\ Maria J Marti \\ Parkinson's Disease and Movement \\ Disorders Unit, Service of Neurology, \\ Institute of Clinical Neurosciences, \\ Hospital Clinic of Barcelona, IDIBAPS, \\ CIBERNED, Spain
}

\begin{abstract}
Movement disorders are a heterogeneous group of neurological conditions, few of which have been classically described as bona fide hereditary illnesses (Huntington's chorea, for instance). Most are considered to be either sporadic or to feature varying degrees of familial aggregation (parkinsonism and dystonia). In the late twentieth century, Mendelian monogenic mutations were found for movement disorders with a clear and consistent family history. Although important, these findings apply only to very rare forms of movement disorders. Already in the twenty-first century, and taking advantage of the modern developments in genetics and molecular biology, growing attention is being paid to the complex genetics of movement disorders. The search for risk genetic variants (polymorphisms) in large cohorts and the identification of different risk variants across different populations and ethnic groups are under way, with the most relevant findings to date corresponding to recent genome wide association studies in Parkinson's disease. These new approaches focusing on risk variants may enable the design of screening tests for early or even preclinical disease, and the identification of likely therapeutic targets.
\end{abstract}

Keywords: genetics, movement disorders, Parkinson's disease, parkinsonism, dystonia

\section{Introduction}

Movement disorders are a group of neurological conditions consisting of abnormal control of voluntary and automatic movements. ${ }^{1}$ According to whether they imply excessive or diminished speed, range and/or accuracy of movements, they can be classified as hyperkinesia or hypokinesia. Chorea and parkinsonism are, respectively, the paradigmatic syndromes of these two categories. Table 1 provides a summary of hyperkinetic and hypokinetic disorders. Movement disorders, taken together, constitute frequent neurological disorders. In particular, Parkinson's disease and essential tremor, whose prevalence range from $1.7 \%$ and $4 \%$ among adults, are the two most frequent movement disorders, with the former being the second most frequent neurodegenerative disease, after Alzheimer's disease. Other types of movement disorders, most importantly dystonia, are much rarer, but still clinically and socially relevant due to the disability they imply. ${ }^{1}$

From an anatomo-functional point of view, movement disorders are generally viewed as a disturbance of the basal ganglia or their connections with other brain structures. Classically, a misbalance between two key basal ganglia neurotransmitters, namely dopamine and acetylcholine, has been used as a model to understand the dichotomy between hypokinesia (lack of dopamine, excess of acetylcholine) and
Correspondence: Maria J Marti

Villarroel I70, Escala 8 Planta 4, 08036,

Barcelona, Catalonia, Spain

Tel +34 932275785

Fax +349322 75783

Email mjmarti@clinic.ub.es which permits unrestricted noncommercial use, provided the original work is properly cited. 
Table I Hypo- and hyperkinesias

\begin{tabular}{ll}
\hline Hypokinesias & Hyperkinesias \\
\hline $\begin{array}{l}\text { Parkinsonism } \\
\text { (bradykinesia, akinesia) }\end{array}$ & Chorea, dystonia, ballism \\
Freezing & Myoclonus, myokymia, myorhythmia \\
Rigidity & Tics \\
Stiffness & Tremor \\
Apraxia & Ataxia (dysmetria) \\
Cataplexy & Akathisia \\
Catatonia, obsessional slowness & Stereotypy \\
\hline
\end{tabular}

hyperkinesia (the opposite), ${ }^{2}$ although nowadays many other neurotransmitters, neuropeptides, and proteins have been implicated.

The last decades of the twentieth century have brought relevant progress in the knowledge of the genetic basis of movement disorders. Not surprisingly, the first movement disorders to be genetically characterized were those that had already, based on their description, been reported as being clearly familial, suggesting the presence of a Mendelian inheritance. Hence, Huntington's disease, a dominant autosomal condition featuring a combination of chorea, psychiatric disturbances and dementia, was found in 1993 to be due to an excessive number of CAG repeats (polyglutaminopathy) within the huntingtin gene (chromosome 4) ${ }^{3,4}$ Almost simultaneously, Wilson's disease, a recessive autosomal disease consisting of abnormal handling of copper mostly leading to familial brain and liver dysfunction which had already been mapped to chromosome 13 almost a decade before, was found to be due to a mutation of the $A T P 7 B$ gene, encoding for a copper-dependent transmembrane ATPase, whose dysfunction leads to defective copper excretion. ${ }^{5-8}$

In contrast, most of the remainder of movement disorders, namely Parkinson's disease (PD) and atypical parkinsonisms,${ }^{9-11}$ along with dystonia, ${ }^{12}$ have been considered as sporadic disorders until recent decades, when the analysis of familial cases has enabled the characterization of a number of classic Mendelian genetic mutations, mostly in PD and primary dystonia. ${ }^{13,14}$ Notwithstanding the undeniable relevance of the identification of these monogenic forms, these account for a small proportion of cases. Thus, at present increasing attention is being paid to the complex genetics of these disorders, putting the stress on common risk genetic variants playing a partial role in these disorders, rather than on rare genetic mutations directly and univocally causing them. In this review, we describe the different strategies that have been used to establish the genetic basis of PD and distonia, as examples of two frequent movement disorders, which has led to a better understanding of the molecular processes involved in these diseases.

\section{Identifying the genetic components underlying the pathophysiology of movement disorders}

Over the past decades, the genetics of movement disorders have been studied in several different ways, including linkage analysis in affected families, sib-pairs analysis, whole genome scanning methods and, through more simple association studies, candidate-gene strategies. Following these research methods, both causative mutations and risk gene variants have been studied. Interestingly, some of these causative or risk genes are common to different movement disorders, mostly parkinsonisms, suggesting that they share some pathophysiological mechanisms. In this section we present a general view of the main genetic research approaches available and suitable for studying movement disorders, mostly focusing on the candidate gene and large-scale methods.

\section{The candidate gene approach}

A traditional method investigating the potential impact of genes on genetic disorders is to perform a study focusing on a candidate gene, which is supposed to be involved in a given disease. The researchers analyze directly the gene or genes that may plausibly be involved in the disease, taking into account the related molecular biology background. ${ }^{15}$ These studies may include members of affected families in order to perform linkage analysis, or alternatively, unrelated cases and controls. In a "case-control" association study, the genotype frequencies of some polymorphisms located in a particular gene are analyzed in order to address whether there is or is not an increased frequency of a single allele or genotype in patients, compared with controls. These polymorphisms most frequently are single nucleotide polymorphisms (SNPs), that is, a change of a single nucleotide in a given region of the genome. The HapMap (http://hapmap.ncbi.nlm.nih.gov/) is a database of the location and frequencies of the SNPs in the human genome in different populations ${ }^{16}$, which are useful to analyze and design genetic associations. An example of successful application of the candidate gene approach is the finding that some polymorphisms of the microtubule associated tau protein $(M A P T)$ gene are associated with PD. ${ }^{17-19}$ This particular gene was considered a candidate gene for $\mathrm{PD}$ after the evidence of its implication in another parkinsonism, progressive supranuclear palsy (PSP).

An alternative to the analysis of polymorphisms is to sequence the codifying exons of a candidate gene, in order to 
find a causative mutation in an affected family, which could be present in the patients, and absent in healthy controls. This was successfully applied in PSP where, besides the above mentioned polymorphisms approach, a complete sequence of the $M A P T$ gene allowed for the identification of mutations leading to a PSP lookalike clinical picture. ${ }^{20}$ Again, this was possibly due to the a priori hypothesis that a causative MAPT mutation could exist in some cases in familial PSP after the observation of the presence of tau aggregates in brain parenchyma of PSP cases and, in a related neurodegenerative disease (frontotemporal dementia with parkinsonism linked to chromosome 17), was already mapped to the $M A P T$ gene. ${ }^{21-23}$

\section{Large-scale approaches}

\section{Genome-wide scan linkage analysis}

The candidate approach is by definition not suitable for diseases where there are no a priori candidate genes. In other instances, it is inefficient, because it is necessary to analyze candidate genes one by one. In contrast, the large-scale approach is unbiased because it does not need an a priori hypothesis about which are the candidate genes or biological pathways involved in the disease.

The basic approach consists of the analysis of the segregation of multiallelic markers, called microsatellites, which are more informative variants than SNPs, and are distributed all over the genome. ${ }^{24} \mathrm{~A}$ set of about 300 microsatellites spaced uniformly along the human genome (Genome Wide Linkage) is the one currently in use. In affected families, 1 or few alleles of microsatellites can eventually be identified to co-segregate with the disease, giving statistical significant values (LOD score). ${ }^{25} \mathrm{~A}$ subsequent analysis of all the genes near this genetic marker could enable the identification of the gene involved in the disease. This linkage approach led to the discovery of $L R R K 2$ gene mutations as a cause of familial PD. ${ }^{26}$

Additionally, the increasing knowledge on human genome variation and the technology advances on SNP genotyping have made it possible to simultaneously examine hundreds of thousands of SNPs in a single DNA chip array (http://www. affymetrix.com/technology/design/index.affx; www.illumina. com). This kind of analysis was successfully performed on a large pedigree affected with Parkinsonian-pyramidal syndrome, which led to the discovery of a disease-associated gene. ${ }^{27}$

\section{Genome-wide scan association analysis}

These new genotyping platforms (the so-called DNA chip arrays) can also be used in case-control association studies. ${ }^{28-30}$ The genome-wide association approach provides an effective and unbiased approach to discovering risk polymorphisms for genetically complex disorders. To perform this type of study it is mandatory to analyze large numbers of cases and controls, to use alleles covering the whole genome that can be inexpensively and efficiently genotyped, and to perform accurate statistical methods for the proper interpretation of such large-scale data. In contrast to the linkage studies, the main premise when performing a genome-wide association study (GWAS) is that extensive common variation in the human genome, exhibited by disease-producing alleles with frequencies greater than $1 \%$, are responsible for the risk of most genetically complex disorders. ${ }^{31,32}$ For instance genetic variants in tau and synuclein ( $S N C A$ ) genes, have been identified as risk factors for PD by using this methodology. This methodology is suitable for settings where the risk effect of these polymorphisms is relatively low but the pathogenic allele variants are frequent in the overall population. ${ }^{28,30}$ The opposite scenario is that of multiple rare allelic variants with low frequencies where this technique is not accurate as even larger cohorts would be necessary to reach enough statistical power, for example, the mutations in the glucocerebrosidase gene, where multiple rare variants cause a high increased risk of suffering familial and nonfamilial PD in a low number of cases. ${ }^{33,34}$

The main difficulty in elucidating the genetic causes and biological processes involved in complex diseases is that probably several factors contribute to their pathophysiology. Some of these genetics factors can either have an additive or an epistatic or multiplicative effect. Epistasis occurs when the effects of one gene are modified by another gene. The presence of epistatic effects is not usually detected with the GWAS approach. ${ }^{35}$ but a number of methods have been developed to tackle epistasis, such as the Hypothesis Free Clinical Cloning (HFCC) analysis which allows for searching genome-wide epistasis in a case-control design under a fast algorithm that tests a variety of different epistatic models in multiple combinations of SNPs. With HFCC samples are split into independent groups, where the analysis is taken further to look for consistent results across the groups. ${ }^{35,36}$ This approach could be explored in future studies to detect the interaction effects of different genes on the risk of parkinsonism.

At present, a number of hypotheses try to explain the different modalities of complex genetic associations. Thus, the common variant/multiple disease (CV/MD) hypothesis postulates that common genetic factors that contribute to a given disease, under a certain combination of interacting genes and environmental factors, may contribute to the risk of another, related, disease when occurring in other genetic 
or environmental backgrounds. ${ }^{31}$ Alternatively, the common disease/rare variant (CD/RV) hypothesis postulates that in some cases, some rare genetic changes with relatively high penetrance, contribute to genetic susceptibility to common diseases. The H1 MAPT haplotype, which is frequent in the normal population and a known risk factor for both PD and PSP (probably depending on additional risk factors as the rs242557 polymorphism, which would act by modifying the final presentation of the parkinsonism) would be an example of the former model,,$^{17,18,37-41}$ whereas the rare glucocerebrosidase mutations that cause Gaucher disease and are also known to increase the risk for $\mathrm{PD}^{42}$ would be an example of the latter.

Finally, it is noteworthy that SNPs are just one source of variation in the human genome. Other types of mutations, like small deletions and insertions of few nucleotides, or large-scale mutations, including gene duplications, chromosomal translocations, and inversions or deletions, could have implications in disease etiology. Specifically, copy-number variants (CNVs) are DNA fragments in which copy-number differences have been found in different genomes, ranging usually from a few hundred bp to several million bp in size. The importance of the CNVs in the total genetic variability and disease-susceptibility in human populations has recently been highlighted. ${ }^{43}$ Therefore, the GWAS SNP association studies could be supplemented with CNVs association analysis, which could be addressed by using the same SNP genotyping platforms. ${ }^{44}$ Other genomic analysis platforms can be used to detect specifically the CNVs, like the genomic hybridization method $(\mathrm{CGH})^{45}$ or isothermic oligonucleotidebased CGH arrays. ${ }^{46}$

\section{Massive sequencing}

The new systems of massive sequencing (http://www.454. com/; http://www.illumina.com/technology/sequencing_ technology.ilmn) make it possible to obtain the complete genomic sequence or, alternatively, to obtain the complete sequence of all the exons of the genes of the genome in a single individual at a reasonable speed. ${ }^{47,48}$ This provides a very informative method of analyzing the human genome, and offers new possibilities in the search for genetic risk or causative factors, which could apply in the future to the study of movement disorders. This approach is particularly useful for studying rare disorders with an expected frequency of mutation $<1 \%$ (Table 2 ), where the sequence of an affected individual can be compared to the SNPs present in healthy controls from the HapMap and dbSNP database (www. ncbi.nih.gov/projects/SNP/), allowing the common SNPs present in healthy subjects to be filterd out, thus removing the noninformative noise. In silico methods allow for analysis of other SNPs to determine the most probable candidate rare variants, depending on their location in the genome and inside the genes, and are investigated in detail to further confirm their pathogenicity. ${ }^{48}$ A new gene causing a rare Mendelian disorder, Miller syndrome, has been identified with this approach. ${ }^{48}$

Furthermore, an ongoing international scientific project, the 1000 Genomes Project (http://www.1000genomes. org/) may have important implications for genetic diseases research. This project consists of massive sequencing of the complete genome of hundreds of individuals from different populations worldwide by using massive sequencing platforms, with the final goal of providing information about the overall human genetic variability, including low frequency polymorphisms in different human populations. The combination of these genotype data with specific data from a GWAS will allow for imputing computationally the genotypes from a given sample for the additional genetic variants of the 1000 Genomes study, without need of direct genotyping. Thus, this information will help to finemap the genetic regions associated with a disease and will suggest, "suspect" SNPs likely to be involved in the studied disease.

\section{Overview of genetics of PD and other parkinsonisms PD}

\section{Monogenic PD}

Monogenic PD is believed to account for around 15\% of cases and includes both dominant and recessive forms (the so-called PARK variants) which are summarized in Table $3 .{ }^{13,49}$ Because this review is devoted to the genetics of movement disorders in general and thus precludes a detailed revision of every single monogenic form of the large variety of known movement disorders, this section focuses on the three monogenic forms of PD considered the more biologically and clinically relevant for a number of reasons.

The first monogenic form of PD (PARK1) was originally detected in 3 unrelated Greek families and 1 Italian kindred with autosomal dominant inherited PD characterized by a typical clinical phenotype but with young age at onset. ${ }^{50}$ The mutation in those families was a single base pair change at position 209 from $\mathrm{G}$ to $\mathrm{A}$ (G209A) resulting in an Ala to Thr substitution at position 53 (A53T) of the alpha-synuclein (SNCA) gene (chromosome 4). ${ }^{50}$ This gene encodes for the homonymous presynaptic nerve protein, which is believed to 
Table 2 Overview of the strategies used in genetic research depending of the disease prevalence and assumptions about the genetic heredity

\begin{tabular}{llll}
\hline & $\begin{array}{l}\text { Preferred first genetic } \\
\text { research approach }\end{array}$ & & $\begin{array}{c}\text { Type of polymorphism } \\
\text { usually analyzed }\end{array}$ \\
\cline { 2 - 3 } & Initial candidate gene & No candidate gene & SNPs, microsatellite \\
\hline $\begin{array}{l}\text { Familial disorder } \\
\text { Hypothesis: risk genetic variant } \\
\text { with a relative high penetrance }\end{array}$ & Linkage analysis & GWS & polymorphism \\
$\begin{array}{l}\text { Sporadic and common disorder } \\
\text { Hypothesis: common risk genetic } \\
\text { variant with a low penetrance }\end{array}$ & Associations studies & GWAS & SNPs, CNVs \\
$\begin{array}{l}\text { Sporadic } \\
\text { Hypothesis: rare risk genetic variant } \\
\text { with a relative high penetrance }\end{array}$ & Sequencing & GWAS-gene & interaction analysis \\
$\begin{array}{l}\text { Sporadic and rare disorder } \\
\text { Hypothesis: common risk genetic } \\
\text { variant }\end{array}$ & ? & Massive sequencing & SNPs, CNVs, microsatellite \\
\hline
\end{tabular}

Abbreviations: GWS, genome wide scan; GWAS, genome wide association study; SNP, single nucleotide polymorphism; CNV, copy number variation.

be involved in synaptic vesicle formation and exocytosis. ${ }^{51}$ The A53T mutation is predicted to disrupt the $\alpha$ helix and extend the $\beta$ sheet structures, thought to be involved in protein misfolding and self-aggregation. Soon after the report of this mutation, and using immunohistochemical techniques, Spillantini et al found that alpha-synuclein is the main component of Lewy bodies and neurites, the histopathological hallmark of Parkinson's disease, suggesting that SNCA and its protein product are key not only to familial but also to sporadic PD. ${ }^{52}$ In recent years a second SNCA mutation in a Basque kindred (E46K) added to the first one, with the peculiarity that those patients developed dementia early in the disease course in contrast to the A53T cases. ${ }^{53}$ The E46 K mutation substitutes glutamic acid with lysine in a highly conserved area of the protein and is, thus, likely to result in protein dysfunction. These first observations of mutations leading to protein misfolding or dysfunction of some type, have been followed in recent years by further reports of SNCA gene duplications and triplications (PARK4). ${ }^{54,55}$
These studies indicate that not only protein dysfunction resulting from gene mutations, but also an overexpression of the protein can enhance protein aggregation and subsequent formation of Lewy bodies. It is noteworthy that cases with gene duplication are very similar to typical PD whereas those with a gene triplication have younger age at onset and associate early dementia, suggesting a dose-response effect for the $S N C A$ gene. However, these $S N C A$ gene mutations and duplications/triplications, albeit clearly relevant for a better knowledge of PD pathophysiology, constitute an infrequent cause of PD.

The second gene mutation causing familial PD was identified in 2 Japanese families carrying homozygous or compound heterozygous exon deletions in the parkin gene (located on chromosome 6; PARK2), which encodes for a protein similar to the ubiquitin family. ${ }^{56}$ It has been speculated that the homozygous mutation of this gene could partly account for a defective function of the proteosome and lead to multi-ubiquitin-like protein aggregates. Carriers of these

Table 3 Summary of monogenic forms of Parkinson's disease (PD)

\begin{tabular}{|c|c|c|c|c|c|}
\hline Name & Disease & Inheritance & Chromosome & Protein & Function \\
\hline PARKI & Familial PD & Autosomal dominant & $4 q 21-q 22$ & $\alpha$-synuclein & Synaptic protein \\
\hline PARK2 & Young-onset PD & Autosomal recessive & $6 q 25.2-q 27$ & Parkin & Ubiquitin-protein ligase \\
\hline PARK4 & Familial PD & Autosomal dominant & $4 q$ region & $\begin{array}{l}\alpha \text {-synuclein duplication } \\
\text { or triplications }\end{array}$ & Synaptic protein \\
\hline PARK5 & Familial PD & Autosomal recessive & $4 p 15$ & $\begin{array}{l}\text { Ubiquitin carboxy-terminal } \\
\text { hydrolase }\end{array}$ & Hydrolase of ubiquitin \\
\hline PARK6 & Young-onset PD & Autosomal recessive & Ip35-p36 & PINK-I & $\begin{array}{l}\text { Mitochondrial anti-stress- } \\
\text { induced degeneration }\end{array}$ \\
\hline PARK7 & Young-onset PD & Autosomal recessive & Ip36 & DJ-I & Sumolyation pathway \\
\hline PARK8 & Familial PD & Autosomal dominant & $|2 p||.2-q| 3 . \mid$ & LRRK2 & Protein phosphorylation \\
\hline GBA & Familial PD & Autosomal dominant & $|q 2|$ & Gluco-cerebrosidase & Membrane lipid \\
\hline
\end{tabular}


homozygous mutations clinically present with a well-defined clinical phenotype: that of autosomal recessive juvenile parkinsonism (AR-JP), which very often starts with kinesigenic foot dystonia and is additionally characterized by a combination of levodopa-responsive parkinsonism, susceptibility to levodopa-induced dyskinesia and motor fluctuations, and a variety of psychiatric symptoms. ${ }^{57}$ This particular clinical phenotype, the juvenile onset, and the lack of Lewy bodies at autopsy, suggest that this is not properly PD and the name "parkin-gene disease" has been proposed to designate these cases. ${ }^{57,58}$ Interestingly, simple heterozygous parkin gene deletion (happloinsufficiency) has also been suggested to be enough in some cases to induce parkinsonism, perhaps acting as a susceptibility or risk factor in conjunction with other genetic or environmental risk factors, but to date this remains an open question. ${ }^{59}$

Finally, in 2004, 2 independent groups reported on a new gene causing autosomal dominant PD (PARK8): the leucine-repeat rich kinase type 2 (LRRK2) gene, initially also named dardarin after the Basque word "dardare" which means tremor (one of the first families identified carrying mutations in these gene was Basque). ${ }^{26,60} L R R K 2$ encodes for a protein member of the ROCO family and although its function is still not fully understood, it is seemingly related to cellular cycle regulation via protein phosphorylation. ${ }^{26}$ The identification of $L R R K 2$ is generally viewed as a relevant contribution to PD genetics for several reasons. First, because $L R R K 2$ mutant PD cases are relatively frequent in familial cases $(6 \%)$ and even in cases otherwise considered as sporadic due to negative family history (between $1 \%$ and nearly 4\%), and are being identified across the different continents and in different ethnic groups. ${ }^{61,62}$ Furthermore, most LRRK2 mutants feature the classic PD clinical picture not only because of their symptoms but also age at onset. All this is in complete contrast to the low prevalence of $S N C A$ mutations and to the fact that parkin-related cases may constitute an independent nosological condition. The above discussed characteristics of $L R R K 2$-related PD make it an attractive model to study the premotor phase of PD. First, the high frequency of a LRRK2 mutations in PD and their variable age at onset make it easy to find healthy mutation carriers and, second, $L R R K 2$ mutation-associated PD are clinically indistinguishable with idiopathic PD, probably having a similar physiopathology. Nonmotor symptoms herald, for many years in some instances, the onset of the cardinal motor signs of the disease and might constitute a very useful means of improving our knowledge of the presumably long preclinical phase of the disease, and eventually assessing candidate preventive or neuroprotective strategies. ${ }^{63}$ However, the fact that the penetrance of the $L R R K 2$ mutations is incomplete (with figures around $60 \%-70 \%$ at $70-80$ years), and that in some instances LRRK2 cases lack underlying Lewy-type pathology, constitute caveats to this approach. ${ }^{26,61,64}$

\section{Complex genetics of PD}

Most of PD cases are still sporadic, though. This, along with compelling evidence that there must also be environmental factors in PD pathogenesis, has suggested that, as in many other human illnesses, complex genetics may be important in PD. ${ }^{65}$ Under a complex genetic model certain genetic variants not causative of disease per se (the so-called gene polymorphisms) might cause minimal dysfunction which might lead to neurodegeneration when interacting with other gene variants, exposure to the aforementioned environmental risk factors, and/or lack of exposure to possible environmental protective factors. ${ }^{65}$ Such might be the case, though still speculative, of the above discussed heterozygote parkin mutations. ${ }^{59}$ Another widely investigated and discussed example would be that of the heterozygous mutations of the glicocerebrosidase gene, responsible for Gaucher's disease, the most frequent lysosomal storage disorder when occurring in homozygosity. ${ }^{66}$ But even before the identification of SNCA mutations, variants of the $M A P T$ (the microtubule associated tau protein) gene, and particularly its $\mathrm{H} 1 \mathrm{H} 1$ haplotype, had been consistently shown as a significant risk factor for PD. ${ }^{17,67}$ This has opened the debate about how this gene is involved in a neurodegenerative disease that does not belong to tauopathies (neurodegenerative diseases where the pathological hallmark is the deposition of tau protein aggregates within the brain). One of the proposed explanations is that the $\mathrm{H} 1 \mathrm{H} 1$ haplotype of the $M A P T$ gene might enhance neuronal loss in $\mathrm{PD}$, whereas other $M A P T$ genetic changes observed in the tauopathies would account for an over-expression of the tau protein itself favoring its hyperphosphorilation and abnormal deposition. ${ }^{41}$

With this premise, and taking advantage of the recent developments in genetics, most remarkably GWAS, several attempts have been made to identify different genetic risk variants in PD. The two largest GWAS published to date, of European and Japanese ancestries respectively have been consistent in: a) the finding that, despite being a rare cause of monogenic PD, the SNCA gene also constitutes a significant risk factor for sporadic PD; b) a trend towards more representation of a $L R R K 2$ polymorphism among $P D$ patients than in the control populations; c) the confirmation of a new locus implicated in PD: PARK16, located in chromosome 
1q32. In contrast they diverge in terms of $M A P T$ association being confirmed as a genetic risk factor for PD in the European study only, whereas the new locus BST1 (located in chromosome $4 \mathrm{p} 15$ ) was identified in the Japanese study solely. ${ }^{29,68}$ However, this latter locus has recently been replicated in both French and Dutch GWAS studies. ${ }^{69,70}$ Other gene variants such as the cyclin G-associated kinase (GAK) are surfacing as relevant PD risk factors in other GWAS association studies..$^{70,71}$

\section{Atypical parkinsonisms}

\section{Monogenetic forms of atypical parkinsonisms}

PSP and multisystem atrophy (MSA) are the most frequent forms of the so-called atypical parkinsonisms, which constitute a difficult and important differential diagnosis with PD. ${ }^{10,11}$

Although no clear monogenic forms of MSA have been identified, an autopsy confirmed case from a German MSA family with involvement of 2 successive generations has been reported, and increased frequency of parkinsonism in first degree relatives has been found among MSA patients in a recent case-control study. ${ }^{72,73}$ Regarding PSP, mutations of the MAPT gene have rarely been associated with a clinical picture of PSP. ${ }^{20,74}$

\section{Complex genetics of atypical parkinsonisms}

As mentioned above, linkage association techniques and the study of SNPs have also helped established the MAPT H1 haplotype and more specifically the H1c subhaplotype (probably more related to the expression of the gene and subsequently with its brain protein-dosage) as a risk factor for PSP, to an even greater extent than PD. ${ }^{68,75,76}$

A SNP association study has found a risk association between the SNCA gene and MSA - again not surprisingly, as MSA is a synucleinopathy in the same way as PD, although the two diseases differ in that in the former the alpha-synuclein aggregates are intraglial (glial citoplasmatic inclusions), and in the latter they are intraneuronal (Lewy bodies and neurites). ${ }^{77}$

Ongoing and future GWAS studies in PSP and MSA are expected to add more information to the complex genetics of both diseases.

\section{Overview of genetics of dystonia}

Dystonia is a movement disorder characterized by involuntary sustained muscle contractions that lead to twisting and repetitive movements and abnormal postures. ${ }^{1}$ According to the etiology, dystonia can be classified as primary torsion dystonia (PTD) and nonprimary dystonia. PTD is a syndrome where only dystonia is present (except for tremor) and there is no evidence of acquired cause or neurodegeneration. Nonprimary dystonia includes the "dystonia plus" (syndromes which are inherited disorders with additional neurological signs besides dystonia, but without neuropathologically detectable lesions), dystonia in heredodegenerative diseases, and dystonia of exogenous causes.

PTD is the most frequent cause of dystonia. Seven genes have been mapped for PTD including DYT1, 2, 4, 6, 13, and 17, but only 2, DYT1 (TOR1A) and DYT6 (THAP1), have been identified. ${ }^{14}$ Most are associated with an early onset generalized phenotype, except for DYT7 and 13, which have been associated with adolescent or adult-onset focal or segmental dystonia. In this section, following the premise of the PD and parkinsonisms section, only DYT1 and 6 are reviewed as the 2 most relevant examples of monogenic forms of dystonia. No information is available yet on complex genetics of dystonia and cooperative national and multinational initiatives are warranted.

\section{DYTI dystonia}

The DYT1-PTD is the most common and severe form of early-onset dystonia. It is a childhood onset disease with a mean age at onset of 12 years. The onset of the disease is often focal with subsequent generalization (65\% of cases) and typically affects legs, trunk and arms, and much more rarely cranial structures. DYT1 dystonia is inherited as an autosomal dominant trait with a reduced penetrance of $\sim 30 \%{ }^{78}$ The disease is caused by an in-frame GAG deletion in the TOR 1 gene, in the long arm of the chromosome 9 (9q34), which removes 1 single glutamic acid residue in the carboxy terminal region of the encoded protein. ${ }^{79}$ The TORI gene is composed of 5 exons and its expressions is regulated by transcription factors of the Ets family. These bind to 2 Ets binding cores in the upstream region of the gene. ${ }^{80}$

TOR1 encoded torsin A, a 332-amino acid protein, is a member of the AAA + family of ATPase, which has been associated with different functions, including protein processing and degradation, intracellular trafficking, vesicle recycling and citoeskeletal dynamics. ${ }^{81}$ Torsin A is widely expressed in human tissues. Both torsin A protein and mRNA have been found in dopaminergic neurons of pars compacta of the susbtantia nigra, and neurons within the cortex, striatum, thalamus, hippocampus, cerebellum, midbrain, pons, and spinal cord ${ }^{82-84}$ A single pathological study carried out in 4 DTY1 dystonia brains found perinuclear inclusion bodies 
in midbrain reticular formation and periaqueductal gray matter, ${ }^{85}$ but so far this finding has not been replicated, with the remainder of pathological studies not having detected any specific abnormalities.

Different studies have indicated that torsin A functions at different subcellullar locations including the nuclear envelope, the endoplasmic reticulum, and secretory and synaptic vesicle compartments. ${ }^{86-91}$ Mutant torsin A has been observed to interfere with the linkage between the nuclear envelope/endoplasmic reticulum membranes and the cytoskeleton, which may affect neurite extension during brain development. ${ }^{91-94}$ Other studies have suggested an abnormal postnatal maturation affecting the neurons (mainly at the synaptic level), ${ }^{91,95}$ but also the glia. ${ }^{97}$

Based on its similarities with the AAA+ATPases and the head shock proteins (HSP), torsin A has also been suggested as likely to act as a chaperone. Torsin A has been found to co-localize with HSPs, ubiquitin and alpha-synuclein in Lewy bodies in patients with Parkinson's disease and its over-expression prevents the formation of alpha-synuclein aggregates in a cell culture model and in polyglutamine repeatinduced protein aggregates in Caenorhabditis elegans. ${ }^{98,99}$

Several studies carried out in different mouse models generated to investigate the role of torsin A in dystonia suggest that the abnormal brain networks in DYT1 dystonia are complex, involving multiple neurotransmitters, and probably areas. ${ }^{101-104}$ In these models, altered levels of dopamine metabolites, ${ }^{101}$ attenuation of release of dopamine after amphetamine stimulation, ${ }^{105}$ and lack of the normal inhibition of cholinergic interneurones activity after D2 dopamine receptor stimulation, ${ }^{106}$ have been detected, indicating that possible impairment between striatal dopaminergic and cholinergic signaling. However, increased levels of serotonin have also been observed. ${ }^{104}$ In agreement with the aforementioned pathological study in human DYT1 dystonia brains, ${ }^{85}$ some of these transgenic animal models have also showed perinuclear inclusions and aggregates of ubiquitin and Torsin A. ${ }^{100,101,104}$ To sum up, and despite the numerous findings from all these studies, it can be concluded that the precise function of torsin $\mathrm{A}$ in dystonia remains elusive.

\section{DYT6 dystonia}

DYT6 dystonia is, like DYT1 dystonia, a dominantly inherited dystonia, but in contrast with the latter condition, at presentation it involves the cranio-cervical musculature and the arms and only rarely the legs. Furthermore, the degree of progression to other regions varies remarkably in DYT6 dystonia. The gene is found in chromosome 8p21-q22 and the overall prevalence of the mutation ranges between $1.0 \%$ and $2.5 \%$ in PTD cohorts variably selected on the basis of family history, early onset, generalization and involvement of laryngeal or cervical regions.

In 2009, Fuchs and coworkers initially reported 2 mutations in the THAP1 gene (THAP domain containing, apoptosis associated protein 1) causing DYT6 dystonia in 4 ancestrally related Amish-Mennonite families and in an unrelated family of German ancestry. ${ }^{107}$ Subsequently, large genetic screening studies have identified more than 45 additional mutations in PTD patients of European Caucasian ancestry, but also in Brazilian and Chinese patients. ${ }^{107-118}$

THAP1 is a member of the THAP (Thanatos-associated protein) family of proteins, which contain an evolutionarily conserved zinc-dependent DNA-binding domain. ${ }^{119-120}$ In addition to the THAP domain at the N-terminus, THAP1 has a low complexity-proline rich region, a coiled-coil domain and nuclear localization signal (NLS) at its C-terminus. Besides its DNA binding function, THAP1 regulates cell proliferation and can function as a nuclear proapoptotic factor, after its interaction with Par-4, a proapoptotic factor linked to prostate cancer and neurodegenerative diseases. ${ }^{120,121}$ There are no specific data on THAP1 function in the brain, though.

Most mutations described in DTY6 are thought to eliminate the DNA-binding function of the protein. These include missense mutations within the DNA binding domain, substitution mutations that disrupt the nuclear localization signal in the C-terminus, or nonsense and frameshift mutations that truncate the protein within the DNA binding domain or before the nuclear localization signal. ${ }^{107,109-118,122} \mathrm{~A}$ smaller number of missense mutations have also been identified in the C-terminal end of the protein and near the coiled-coil domain. ${ }^{109,113-117}$

The nuclear localization of THAP1 suggests a potential interaction with torsin-1A and related pathways. In this sense, 2 studies have reported an interaction between THAP1 and TOR $1 A$. THAP1 protein binds directly to the TOR $1 A$ promoter in cell lines, primary cells and mouse brain tissue and this interaction is disrupted by pathogenic THAP1 mutations. ${ }^{122}$ In addition wild-type THAP1 represses the expression of TOR1, whereas dystonia-associated mutant THAP 1 results in decreased repression of TOR $1 .{ }^{123}$ These data indicate transcriptional dysregulation as a cause of dystonia and link the molecular pathways of DYT1 and DYT6 in dystonia.

\section{Identifying targets for new therapies}

Genes or proteins involved in the pathological process of a particular disease are possible targets for drug 
development and subsequently for clinical trials. For instance, alpha-synuclein is an obvious target for the development of pharmacological interventions in PD and related disorders also featuring alpha-synuclein brain deposition. Therefore, elucidating the exact biological mechanisms by which alphasynuclein causes or is associated with neurodegeneration, or the upstream molecular events that eventually lead to alpha-synuclein alteration, would have a great impact on the design of new disease-modifying drugs or strategies. However, the mechanisms by which alpha-synuclein leads to neurodegeneration still remain elusive, as it has been proposed that enhanced rates of fibrillar a-synuclein and their deposition on Lewy bodies could well be the cause of the neurotoxicity, but other studies have suggested that small prefibrillar oligomers of alpha-synuclein might be the actual toxic species. ${ }^{125}$ Nevertheless, SNCA mutations causing PD in a dominant manner are extremely rare, and other additional genes with different or unknown functions have been implicated in familial PD, in some instances without underlying alpha-synuclein deposition or Lewy bodies (parkin and some cases of LRRK2). ${ }^{26,58,64}$ Furthermore, some of these genes are involved in proteosome or autophagic process (parkin, $L R R K 2, D J 1$ ), thus suggesting that they could be involved in the incorrect processing of misfolded or aggregated alphasynuclein. ${ }^{125}$ Therefore those events, likely to lay upstream of synuclein deposition, could also be targets of pharmacological intervention. Finally, mutations in parkin, LRRK2, $D J 1$, and PINK1 genes have been described to produce mitochondrial alterations, specifically in the complex I of the mitochondrial respiratory chain, suggesting that antioxidant treatments or modulators of mitochondria function could be candidate strategies for treating PD as well. ${ }^{126-130}$

In addition, under the CV/MD hypothesis, other parkinsonisms that would share with PD common genetic risk factors could also have similar underlying altered biological systems. For instance, there is recent evidence that mitochondrial dysfunction, largely addressed in PD, may also be impaired in PSP and in dementia with Lewy bodies, and the same may apply for proteosome dysfunction in MSA and PSP. ${ }^{131-133}$ However, the complete and precise picture of all the events occurring in these different diseases, and which are affecting each biological system likely to be involved, such as the mitochondria, oxidative stress, autophagy, proteosome, and final alpha-synuclein deposition, are not fully understood yet.

\section{Conclusion}

In recent years, relevant progress in the knowledge of the genetic basis of movement disorders has been achieved.
Using different genetic studies different causative Mendelian gene mutations have been identified and more recently growing attention is being paid to genetic risk variants of these diseases. In complex diseases, like PD, a combination of genetic causative or risk factors, and interactions between these risk factors, could be involved in the etiology of the disease. The prevalence of each disease, together with our assumptions about the characteristics and frequencies of the genetic variants in the affected populations, will condition the research methods to be prioritized. In addition, common genetic factors are involved in different related diseases and could show common pathological biological pathways. The finding of the parkinsonism-associated pathways will allow developing animal or cell models of these conditions, in order to focus research on the related molecular mechanisms, which could eventually lead to the identification of therapeutic targets.

\section{Disclosure}

The authors declare no conflicts of interest in this work.

\section{References}

1. Fahn S, Jankovic J. Clinical overview and phenomenology of movement disorders. In: Fahn S, Jankovic J, Principles and Practice of Movement Disorders. Philadelphia, PA: Churchill Livingstone Elsevier; 2007.

2. Burn JH. Levodopa and anticholinergic drugs in Parkinsonism. Br Med J. 1971;2(5764):773-774.

3. Huntington G. On chorea. Med Surg Reporter. 1872;(26):320-321.

4. A novel gene containing a trinucleotide repeat that is expanded and unstable on Huntington's disease chromosome. The Huntington's Disease Collaborative Research Group. Cell. 1993;72(6):971-983.

5. Wilson SAK. Progressive lenticular degeneration: a familial nervous disease associated with cirrhosis of the liver. Brain. 1912;(34):295-509.

6. Frydman M, Bonne-Tamir B, Farrer LA, et al. Assignment of the gene for Wilson disease to chromosome 13: linkage to the esterase D locus. Proc Natl Acad Sci US A. 1985;82(6):1819-1821.

7. Bull PC, Thomas GR, Rommens JM, Forbes JR, Cox DW. The Wilson disease gene is a putative copper transporting P-type ATPase similar to the Menkes gene. Nat Genet. 1993;5(4):327-337.

8. Tanzi RE, Petrukhin K, Chernov I, et al. The Wilson disease gene is a copper transporting ATPase with homology to the Menkes disease gene. Nat Genet. 1993;5(4):344-350.

9. Parkinson J. An essay on the shaking palsy. London: Sherwood, Neely, and Jones; 1817.

10. Steele JC, Richardson JC, Olszewski J. Progressive supranuclear palsy. A heterogeneous degeneration involving the brain stem, basal ganglia and cerebellum with vertical gaze and pseudobulbar palsy, nuchal dystonia and dementia. Arch Neurol. 1964;10:333-359.

11. Shy GM, Drager GA. A neurological syndrome associated with orthostatic hypotension: a clinical-pathologic study. Arch Neurol. 1960;2: 511-527.

12. Oppenheim H. Über eine eigenartige Krampfrankheit des kindlichen und jugendlichen Alters (Dysbasia lordotica progressiva, Dystonia musculorum deformans). Neurol Centrabl. 1911;30:1090-1107.

13. Gasser T. Mendelian forms of Parkinson's disease. Biochim Biophys Acta. 2009;1792(7):587-596.

14. Müller U. The monogenic primary dystonias. Brain. 2009;132(Pt 8): 2005-2025. 
15. Kwon JM, Goate AM. The candidate gene approach. Alcohol Res Health. 2000;4(3):164-168.

16. The International HapMap Consortium. The International HapMap Project. Nature. 2003;426(6968):789-796.

17. Pastor P, Ezquerra M, Muñoz E, et al. Significant association between the tau gene A0/A0 genotype and Parkinson's disease. Ann Neurol. 2000;47(2):242-245.

18. Farrer M, Maraganore DM, Lockhart P, et al. alpha-Synuclein gene haplotypes are associated with Parkinson's disease. Hum Mol Genet. 2001;10(17):1847-1851.

19. Ezquerra M, Pastor P, Gaig C, et al. Different MAPT haplotypes are associated with Parkinson's disease and progressive supranuclear palsy. Neurobiol Aging. 2011;32(547):e11-e16.

20. Morris HR, Osaki Y, Holton J, et al. Tau exon 10+16 mutation FTDP-17 presenting clinically as sporadic young onset PSP. Neurology. 2003; 61(1):102-104.

21. Poorkaj P, Bird TD, Wijsman E, et al. Tau is a candidate gene for chromosome 17 frontotemporal dementia. Ann Neurol. 1998;43(6): $815-825$.

22. Conrad C, Andreadis A, Trojanowski JQ, et al. Genetic evidence for the involvement of tau in progressive supranuclear palsy. Ann Neurol. 1997;41(2):277-281.

23. Flament S, Delacourte A, Verny M, Hauw JJ, Javoy-Agid F. Abnormal Tau proteins in progressive supranuclear palsy. Similarities and differences with the neurofibrillary degeneration of the Alzheimer type. Acta Neuropathol. 1991;81(6):591-596.

24. Hearne CM, Ghosh S, Todd JA. Microsatellites for linkage analysis of genetic traits. Trends Genet. 1992;8(8):288-294.

25. Altshuler D, Daly MJ, Lander ES. Genetic mapping in human disease. Science. 2008;322(5903):881-888.

26. Zimprich A, Biskup S, Leitner P, et al. Mutations in LRRK2 cause autosomal-dominant parkinsonism with pleomorphic pathology. Neuron. 2004;44(4):601-607.

27. Sina F, Banihosseini SS, Kazemi MH, et al. Genome-wide linkage analysis of a Parkinsonian-pyramidal syndrome pedigree by $500 \mathrm{~K}$ SNP arrays. Am J Hum Genet. 2008;82(6):1375-1384.

28. Pankratz N, Wilk JB, Latourelle JC, et al. PSG-PROGENI and GenePD Investigators, Coordinators and Molecular Genetic Laboratories. Genome-wide association study for susceptibility genes contributing to familial Parkinson disease. Hum Genet. 2009;124(6):593-605.

29. Sieh W, Choi Y, Chapman NH, et al. Identification of novel susceptibility loci for Guam neurodegenerative disease: challenges of genome scans in genetic isolates. Hum Mol Genet. 2009;18(19):3725-3738.

30. Simón-Sánchez J, Schulte C, Bras JM, et al. Genome-wide association study reveals genetic risk underlying Parkinson's disease. Nat Genet. 2009;41(12):1308-1312.

31. Becker KG. The common variants/multiple disease hypothesis of common complex genetic disorders. Med Hypotheses. 2004;62(2): 309-317.

32. Cantor RM, Lange K, Sinsheimer JS. Prioritizing GWAS results: A review of statistical methods and recommendations for their application. Am J Hum Genet. 2010;86(1):6-22.

33. Clark LN, Ross BM, Wang Y, et al. Mutations in the glucocerebrosidase gene are associated with early-onset Parkinson disease. Neurology. 2007;69(12):1270-1277.

34. Sato C, Morgan A, Lang AE, et al. Analysis of the glucocerebrosidase gene in Parkinson's disease. Mov Disord. 2005;20(3):367-370.

35. Gayán J, González-Pérez A, Bermudo F, et al. A method for detecting epistasis in genome-wide studies using case-control multi-locus association analysis. BMC Genomics. 2008;9:360.

36. González-Pérez A, Gayán J, Marín J, et al. Whole-genome conditional two-locus analysis identifies novel candidate genes for late-onset Parkinson's disease. Neurogenetics. 2009;10(3):173-181.

37. Fung HC, Xiromerisiou G, Gibbs JR, et al. Association of tau haplotype-tagging polymorphisms with Parkinson's disease in diverse ethnic Parkinson's disease cohorts. Neurodegener Dis. 2006;3(6):327-333.
38. Baker M, Litvan I, Houlden H, et al. Association of an extended haplotype in the tau gene with progressive supranuclear palsy. Hum Mol Genet. 1999;8(4):711-715.

39. Pastor P, Ezquerra M, Tolosa E, et al. Further extension of the $\mathrm{H} 1$ haplotype associated with progressive supranuclear palsy. Mov Disord. 2002;17(3):550-556.

40. Cruchaga C, Vidal-Taboada JM, Ezquerra M, et al. Iberian Atypical Parkinsonism Study Group Researchers. 5'-Upstream variants of CRHR1 and MAPT genes associated with age at onset in progressive supranuclear palsy and cortical basal degeneration. Neurobiol Dis. 2009;33(2):164-170.

41. Vandrovcova J, Anaya F, Kay V, Lees A, Hardy J, de Silva R. Disentangling the Role of the tau Gene Locus in Sporadic Tauopathies. Curr Alzheimer Res. 2010;7(8):726-734.

42. Aharon-Peretz J, Rosenbaum H, Gershoni-Baruch R. Mutations in the glucocerebrosidase gene and Parkinson's disease in Ashkenazi Jews. N Engl J Med. 2004;351(19):1972-1977.

43. Ionita-Laza I, Rogers AJ, Lange C, Raby BA, Lee C. Genetic association analysis of copy-number variation $(\mathrm{CNV})$ in human disease pathogenesis. Genomics. 2009;93(1):22-26.

44. Komura D, Shen F, Ishikawa S, et al. Genome-wide detection of human copy number variations using high-density DNA oligonucleotide arrays. Genome Res. 2006;16(12):1575-1584.

45. Fiegler H, Redon R, Andrews D, et al. Accurate and reliable highthroughput detection of copy number variation in the human genome. Genome Res. 2006;16(12):1566-1574.

46. Carvalho B, Ouwerkerk E, Meijer GA, Ylstra B. High resolution microarray comparative genomic hybridisation analysis using spotted oligonucleotides. J Clin Pathol. 2004;57(6):644-646.

47. $\mathrm{Ng} \mathrm{SB}$, Buckingham $\mathrm{KJ}$, Lee C, et al. Exome sequencing identifies the cause of a mendelian disorder. Nat Genet. 2010;42(1):30-35.

48. Wheeler DA, Srinivasan M, Egholm M, et al. The complete genome of an individual by massively parallel DNA sequencing. Nature. 2008; 452(7189):872-876.

49. Alcalay RN, Caccappolo E, Mejia-Santana H, et al. Frequency of known mutations in early-onset Parkinson disease: implication for genetic counseling: the consortium on risk for early onset Parkinson disease study. Arch Neurol. 2010;67(9):1116-1122.

50. Polymeropoulos MH, Lavedan C, Leroy E, et al. Mutation in the alphasynuclein gene identified in families with Parkinson's disease. Science. 1997;276(5321):2045-2047.

51. Clayton DF, George JM. The synucleins: a family of proteins involved in synaptic function, plasticity, neurodegeneration and disease. Trends Neurosci. 1998;21(6):249-254.

52. Spillantini MG, Schmidt ML, Lee VM, Trojanowski JQ, Jakes R, Goedert M. Alpha-synuclein in Lewy bodies. Nature. 1997;388(6645): 839-840.

53. Zarranz JJ, Alegre J, Gómez-Esteban JC, et al. The new mutation, E46K, of alpha-synuclein causes Parkinson and Lewy body dementia. Ann Neurol. 2004;55(2):164-173.

54. Chartier-Harlin MC, Kachergus J, Roumier C, et al. Alpha-synuclein locus duplication as a cause of familial Parkinson's disease. Lancet. 2004;364(9440):1167-1169.

55. Singleton AB, Farrer M, Johnson J, et al. alpha-Synuclein locus triplication causes Parkinson's disease. Science. 2003;302(5646): 841.

56. Kitada T, Asakawa S, Hattori N, et al. Mutations in the parkin gene cause autosomal recessive juvenile parkinsonism. Nature. 1998;392(6676): 605-608.

57. Khan NL, Graham E, Critchley P, et al. Parkin disease: a phenotypic study of a large case series. Brain. 2003;126(Pt 6):1279-1292.

58. Takahashi H, Ohama E, Suzuki S, et al. Familial juvenile parkinsonism: clinical and pathologic study in a family. Neurology. 1994;44(3 Pt 1): 437-441.

59. West A, Periquet M, Lincoln S, et al. French Parkinson's Disease Genetics Study Group and the European Consortium on Genetic Susceptibility on Parkinson's Disease. Complex relationship between Parkin mutations and Parkinson disease. Am J Med Genet. 2002;114(5): 584-591. 
60. Paisán-Ruíz C, Jain S, Evans EW, et al. Cloning of the gene containing mutations that cause PARK8-linked Parkinson's disease. Neuron. 2004; 44(4):595-600.

61. Healy DG, Falchi M, O'Sullivan SS, et al. International LRRK2 Consortium. Phenotype, genotype, and worldwide genetic penetrance of LRRK2-associated Parkinson's disease: a case-control study. Lancet Neurol. 2008;7(7):583-590.

62. Gaig C, Ezquerra M, Marti MJ, Muñoz E, Valldeoriola F, Tolosa E. LRRK2 mutations in Spanish patients with Parkinson disease: frequency, clinical features, and incomplete penetrance. Arch Neurol. 2006;63(3):377-382.

63. Tolosa E, Gaig C, Santamaría J, Compta Y. Diagnosis and the premotor phase of Parkinson disease. Neurology. 2009;72(7 Suppl): S12-S20.

64. Gaig C, Martí MJ, Ezquerra M, Rey MJ, Cardozo A, Tolosa E. G2019S LRRK2 mutation causing Parkinson's disease without Lewy bodies. J Neurol Neurosurg Psychiatry. 2007;78(6):626-628.

65. Chade AR, Kasten M, Tanner CM. Nongenetic causes of Parkinson's disease. J Neural Transm Suppl. 2006;70:147-151.

66. Neumann J, Bras J, Deas E, et al. Glucocerebrosidase mutations in clinical and pathologically proven Parkinson's disease. Brain. 2009;132 (Pt 7):1783-1794.

67. Healy DG, Abou-Sleiman PM, Lees AJ, et al. Tau gene and Parkinson's disease: a case-control study and meta-analysis. J Neurol Neurosurg Psychiatry. 2004;75(7):962-965.

68. Satake W, Nakabayashi Y, Mizuta I, et al. Genome-wide association study identifies common variants at four loci as genetic risk factors for Parkinson's disease. Nat Genet. 2009;41(12):1303-1307.

69. Saad M, Lesage S, Saint-Pierre A, et al; French Parkinson's Disease Genetics Study Group. Genome-wide association study confirms BST1 and suggests a locus on 12q24 as the risk loci for Parkinson's disease in the European population. Hum Mol Genet. 2011;20(3): 615-627.

70. Simón-Sánchez J, van Hilten JJ, van de Warrenburg B, et al. Genomewide association study confirms extant PD risk loci among the Dutch. Eur J Hum Genet. 2011 Jan 19. [Epub ahead of print].

71. Rhodes SL, Sinsheimer JS, Bordelon Y, Bronstein JM, Ritz B Replication of GWAS Associations for GAK and MAPT in Parkinson's Disease. Ann Hum Genet. 2011;75(2):195-200.

72. Wüllner U, Schmitt I, Kammal M, Kretzschmar HA, Neumann M. Definite multiple system atrophy in a German family. J Neurol Neurosurg Psychiatry. 2009;80(4):449-450.

73. Vidal JS, Vidailhet M, Derkinderen P, Tzourio C, Alpérovitch A. Familial aggregation in atypical Parkinson's disease: a case control study in multiple system atrophy and progressive supranuclear palsy. J Neurol. 2010;257(8):1388-1393.

74. Pastor P, Pastor E, Carnero C, et al. Familial atypical progressive supranuclear palsy associated with homozigosity for the delN296 mutation in the tau gene. Ann Neurol. 2001;49:263-267.

75. Pittman AM, Myers AJ, Abou-Sleiman P, et al. Linkage disequilibrium fine mapping and haplotype association analysis of the tau gene in progressive supranuclear palsy and corticobasal degeneration. $\mathrm{J} \mathrm{Med}$ Genet. 2005;42(11):837-846.

76. Rademakers R, Melquist S, Cruts M, et al. High-density SNP haplotyping suggests altered regulation of tau gene expression in progressive supranuclear palsy. Hum Mol Genet. 2005;14(21):3281-3292.

77. Scholz SW, Houlden H, Schulte C, et al. SNCA variants are associated with increased risk for multiple system atrophy. Ann Neurol. 2009; 65(5):610-614.

78. Bressman SB, de Leon D, Brin MF, et al. Idiopathic dystonia among Ashkenazi Jews: evidence for autosomal dominant inheritance. Ann Neurol. 1989;26(5):612-620.

79. Ozelius LJ, Page CE, Klein C, et al. The TOR1A (DYT1) gene family and its role in early onset torsion dystonia. Genomics. 1999;62(3): 377-384

80. Armata IA, Ananthanarayanan M, Balasubramaniyan N, Shashidharan P. Regulation of DYT1 gene expression by the Ets family of transcription factors. J Neurochem. 2008;106(3):1052-1065.
81. Vale RD. AAA proteins. Lords of the ring. J Cell Biol. 2000;150(1): 13-19.

82. Augood SJ, Penney JB Jr, Friberg IK, et al. Expression of the early-onset torsion dystonia Gene (DYT1) in human brain. Ann Neurol. 1998;43(5):669-673.

83. Augood SJ, Martin DM, Ozelius LJ, Breakefield XO, Penney JB Jr, Standaert DG. Distribution of the MRNAs encoding TorsinA and TorsinB in the normal adult human brain. Ann Neurol. 1999;46(5): 761-769.

84. Konakova M, Huynh DP, Yong W, Pulst SM. Cellular distribution of torsin A and torsin B in normal human brain. Arch Neurol. 2001; 58(6):921-927.

85. McNaught KS, Kapustin A, Jackson T, et al. Brainstem pathology in DYT1 primary torsion dystonia. Ann Neurol. 2004;56(4):540-547.

86. Goodchild RE, Dauer WT. Mislocalization to the nuclear envelope: an effect of the dystonia-causing torsinA mutation. Proc Natl Acad Sci U S A. 2004;101(3):847-852.

87. Naismith TV, Heuser JE, Breakefield XO, Hanson PI. TorsinA in the nuclear envelope. Proc Natl Acad Sci U S A. 2004;101(20): $7612-7617$

88. Hewett J, Ziefer P, Bergeron D, et al. TorsinA in PC12 cells: localization in the endoplasmic reticulum and response to stress. J Neurosci Res. 2003;72(2):158-168.

89. Hewett JW, Tannous B, Niland BP, et al. Mutant torsinA interferes with protein processing through the secretory pathway in DYT1 dystonia cells. Proc Natl Acad Sci U S A. 2007;104(17):7271-7276.

90. Hewett JW, Nery FC, Niland B, et al. SiRNA knockdown of mutant torsinA restores processing through secretory pathway in DYT1 dystonia cells. Hum Mol Genet. 2008;17(10):1436-1445.

91. Kamm C, Boston H, Hewett J, et al. The early onset dystonia protein torsinA interacts with kinesin light chain 1. J Biol Chem. 2004; 279(19):19882-19892.

92. Hewett JW, Zeng J, Niland BP, Bragg DC, Breakefield XO. Dystoniacausing mutant torsin A inhibits cell adhesion and neurite extension through interference with cytoskeletal dynamics. Neurobiol Dis. 2008; 22(1):98-111.

93. Hewett JW, Tannous B, Niland BP, Nery FC, Breakefield XO. Mutant torsinA interferes with protein processing through the secretory pathway in DYT1 dystonia cells. Proc Natl Acad Sci U SA. 2007;104(17): 7271-7276.

94. Nery FC, Zeng J, Niland BP, et al. TorsinA involvement in linkage between nuclear envelope and intermediate filaments in cytoplasm. J Cell Sci. 2008;121(Pt 20):3476-3486.

95. Lee DW, Seo JB, Ganetzky B, Koh YH. DeltaFY mutation in human torsinA induces locomotor disability and abberant synaptic structures in Drosophila. Mol Cells. 2009;27(1):89-97.

96. Granata A, Watson R, Collinson LM, et al. The dystonia-associated protein torsin A modulates synaptic vesicle recycling. J Biol Chem. 2008;283(12):7568-7579.

97. Zhao Y, Xiao J, Ueda M, et al. Glial elements contribute to stressinduced torsinA expression in the CNS and peripheral nervous system. Neuroscience. 2008;155(2):439-453.

98. McLean PJ, Kawamata H, Shariff S, et al. TorsinA and heat shock proteins act as molecular chaperones: supresión of alpha-synuclein aggregation. J Neurochem. 2002;83(4):846-854.

99. Caldwell GA, Cao S, Sexton EG, Gelwix CC, Bevel JP, Caldwell KA. Suppression of polyglutamine-induced protein aggregation in caenorhabditis elegans by torsin proteins. Hum Mol Genet. 2003;12(3): 307-319.

100. Shashidharan P, Sandu D, Potla U, et al. Transgenic mouse model of early-onset DYT1 dystonia. Hum Mol Genet. 2005;14(1): 125-133.

101. Dang MT, Yokoi F, McNaught KS, et al. Generation and characterization of Dyt1 DeltaGAG knock-in Mouse is a model for early-onset dystonia. Exp Neurol. 2005;196(2):452-463.

102. Dang MT, Yokoi F, Pence MA, Li Y. Motor deficits and hyperactivity in Dyt1 knockdown mice. Neurosci Res. 2006;56(4):470-474. 
103. Goodchild RE, Kim CE, Dauer WT. Loss of the dystonia- associated protein torsinA selectively disrupts the neuronal nuclear envelope. Neuron. 2005;48(6):923-932.

104. Grundmann K, Reischmann B, Vanhoutte G, et al. Overexpression of human wildtype torsinA and human Delta- GAG torsinA in a transgenic mouse model causes phenotypic abnormalities. Neurobiol Dis. 2007;27(2):190-206.

105. Balcioglu A, Kim MO, Sharma N, Cha JH, Breakefield XO, Standaert DG. Dopamine release is impaired in a mouse model of DYT1 dystonia. J Neurochem. 2007;102(3):783-788.

106. Pisani A, Martella G, Tscherter A, et al. Altered responses to dopaminergic D2 receptor activation and Ntype calcium currents in striatal cholinergic interneurons in a mouse model of DYT1 dystonia. Neurobiol Dis. 2006;24(2):318-325.

107. Fuchs T, Gavarini S, Saunders-Pullman R, et al. Mutations in the THAP1 gene are responsible for DYT6 primary torsion dystonia. Nat Genet. 2009;41(3):286-288.

108. Bonetti M, Barzaghi C, Brancati F, et al. Mutation screening of DYT6/ THAP1 gene in Italy. Mov Disord. 2009;24(16):2424-2427.

109. Bressman SB, Raymond D, Fuchs T, Heiman GA, Ozelius LJ, Saunders-Pullman R. Mutations in THAP1 (DYT6) in early-onset dystonia: a genetic screening study. Lancet Neurol. 2009;8(5):441-446.

110. Djarmati A, Schneider SA, Lohmann K, et al. Mutations in THAP1 (DYT6) and generalised dystonia with prominent spasmodic dysphonia: a genetic screening study. Lancet Neurol. 2009;8(5): 447-452.

111. Paisán-Ruiz C, Ruiz-Martinez J, Ruibal M, et al. Identification of a novel THAP1 mutation at R29 amino-acid residue in sporadicpatients with early-onset dystonia. Mov Disord. 2009;24(16):2428-2429.

112. Clot F, Grabli D, Burbaud P, et al. Screening of the THAP1 gene in patients with early-onset dystonia: myoclonic jerks are part of the dystonia 6 phenotype. Neurogenetics. 2011;12(1):87-89.

113. Groen JL, Ritz K, Contarino MF, et al. DYT6 dystonia: Mutation screening, phenotype, and response to deep brain stimulation. Mov Disord. 2010;25(14):2420-2427.

114. Houlden H, Schneider SA, Paudel R, et al. THAP1 mutations (DYT6) are an additional cause of early-onset dystonia. Neurology. 2010; 74(10):846-850.

115. Söhn AS, Glöckle N, Doetzer AD, et al. Prevalence ofTHAP1 sequence variants in German patients with primary dystonia. Mov Disord. 2010; 25(12):1982-1986.

116. Xiao J, Zhao Y, Bastian RW, et al. Novel THAP1 sequence variants in primary dystonia. Neurology. 2010;74(3):229-238.

117. De Carvalho Aguiar P, Fuchs T, Borges V, et al. Screening of Brazilian families with primary dystonia reveals a novel THAP1 mutation and a de novo TOR1 A GAG deletion. Mov Disord. 2010;25(16): 2854-2857.

118. Cheng FB, Wan XH, Feng JC, Wang L, Yang YM, Cui LY. Clinical and genetic evaluation of DYT1 and DYT6 primary dystonia in China. Eur J Neurol. 2011;18(3):497-503.
119. Clouaire T, Roussigne M, Ecochard V, Mathe C, Amalric F, Girard JP. The THAP domain of THAP1 is a large $\mathrm{C} 2 \mathrm{CH}$ module with zincdependent sequence-specific DNA-binding activity. Proc Natl Acad Sci U S A. 2005;102(19):6907-6912.

120. Roussigne M, Cayrol C, Clouaire T, Amalric F, Girard JP. THAP1 is a nuclear proapoptotic factor that links prostate-apoptosis-response-4 (Par-4) to PML nuclear bodies. Oncogene. 2003;22(16):2432-2442.

121. Cayrol C, Lacroix $C$, Mathe $C$, et al. The THAP-zinc finger protein THAP1 regulates endothelial cell proliferation through modulation of pRB/E2F cell-cycle target genes. Blood. 2007;109(2):584-594.

122. Gavarini S, Cayrol C, Fuchs T, et al. Direct interaction between causative genes of DYT1 and DYT6 primary dystonia. Ann Neurol. 2010;68(4):456-461.

123. Kaiser FJ, Osmanovic A, Rakovic A, et al. The dystonia gene DYT1 is repressed by the transcription factor THAP1 (DYT6). Ann Neurol. 2010;8(4):554-559.

124. Gosavi N, Lee HJ, Lee JS, Patel S, Lee SJ. Golgi fragmentation occurs in the cells with prefibrillar alpha-synuclein aggregates and precedes the formation of fibrillar inclusion. J Biol Chem. 2002;277(50): 48984-48992.

125. Ren H, Fu K, Mu C, Li B, Wang D, Wang G. DJ-1, a cancer and Parkinson's disease associated protein, regulates autophagy through JNK pathway in cancer cells. Cancer Lett. 2010;297(1):101-108.

126. Mortiboys H, Thomas KJ, Koopman WJ, et al. Mitochondrial function and morphology are impaired in parkin-mutant fibroblasts. Ann Neurol. 2008;64(5):555-565.

127. Mortiboys H, Johansen KK, Aasly JO, Bandmann O. Mitochondrial impairment in patients with Parkinson disease with the G2019S mutation in LRRK2. Neurology. 2010;75(22):2017-2020.

128. Irrcher I, Aleyasin H, Seifert EL, et al. Loss of the Parkinson's diseaselinked gene DJ-1 perturbs mitochondrial dynamics. Hum Mol Genet. 2010;19(19):3734-3746

129. Morais VA, Verstreken P, Roethig A, et al. Parkinson's disease mutations in PINK1 result in decreased Complex I activity and deficient synaptic function. EMBO Mol Med. 2009;1(2):99-111.

130. Murphy AN. In a flurry of PINK, mitochondrial bioenergetics takes a leading role in Parkinson's disease. EMBO Mol Med. 2009;1(2):81-84.

131. Albers DS, Beal MF. Mitochondrial dysfunction in progressive supranuclear palsy. Neurochem Int. 2002;40(6):559-564.

132. Navarro A, Boveris A, Bández MJ, et al. Human brain cortex: mitochondrial oxidative damage and adaptive response in Parkinson disease and in dementia with Lewy bodies. Free Radic Biol Med. 2009;46(12): 1574-1580.

133. Bukhatwa S, Zeng BY, Rose S, Jenner P. A comparison of changes in proteasomal subunit expression in the substantia nigra in Parkinson's disease, multiple system atrophy and progressive supranuclear palsy. Brain Res. 2010;(1326):174-183.
The Application of Clinical Genetics

\section{Publish your work in this journal}

The Application of Clinical Genetics is an international, peer-reviewed open access journal that welcomes laboratory and clinical findings in the field of human genetics. Specific topics include: Population genetics; Functional genetics; Natural history of genetic disease; Management of genetic disease; Mechanisms of genetic disease; Counselling and

\section{Dovepress}

ethical issues; Animal models; Pharmacogenetics; Prenatal diagnosis; Dysmorphology. The manuscript management system is completely online and includes a very quick and fair peer-review system, which is all easy to use. Visit http://www.dovepress.com/testimonials.php to read real quotes from published authors. 